\title{
A Proposed Information System for Communicating Foot-and-Mouth Disease Events among Livestock Stakeholders in Gairo District, Morogoro Region, Tanzania
}

\author{
Ahmed Kijazi $\mathbb{D}^{1,2}$ Michael Kisangiri, ${ }^{1,2}$ Shubi Kaijage ${ }^{(D)},{ }^{1}$ and Gabriel Shirima ${ }^{3}$ \\ ${ }^{1}$ School of Computational and Communication Science and Engineering (CoCSE), \\ The Nelson Mandela African Institution of Science and Technology, Arusha, Tanzania \\ ${ }^{2}$ Mathematics and ICT Department, College of Business Education (CBE), Dar es Salaam, Tanzania \\ ${ }^{3}$ School of Life Sciences and Bioengineering (LiSBE), \\ The Nelson Mandela African Institution of Science and Technology (NM-AIST), Arusha, Tanzania \\ Correspondence should be addressed to Ahmed Kijazi; ahmedk@nm-aist.ac.tz
}

Received 4 July 2020; Revised 22 February 2021; Accepted 26 March 2021; Published 21 April 2021

Academic Editor: Marco Porta

Copyright ( $\odot 2021$ Ahmed Kijazi et al. This is an open access article distributed under the Creative Commons Attribution License, which permits unrestricted use, distribution, and reproduction in any medium, provided the original work is properly cited.

\begin{abstract}
Foot-and-Mouth Disease (FMD) is present in many countries globally, including Tanzania, especially Gairo district. The data shows that $78 \%$ of livestock keepers in Gairo district had already observed FMD infection in their cattle, and the pastoral communities were mostly affected. Currently, vaccination is the main tool for controlling FMD because there are no therapeutic intervention tools. Therefore, effective communication among livestock stakeholders can be used as an essential tool of preparedness for the disease's impact. This study had two specific objectives: (i) to explore the challenges of communicating FMD events among livestock keepers and other livestock stakeholders in Gairo district and (ii) to propose an information system for sharing FMD events among the livestock stakeholders in Gairo district. The study found that there was a delay when communicating FMD events in Gairo district due to the long chain of information flow. Therefore, the system aims to reduce the communication chain by allowing livestock keepers to report disease outbreaks directly to the system. Livestock keepers may also access FMD precaution measures, negative impacts, clinical signs transmission ways, and current outbreaks directly from the system using Unstructured Supplementary Service Data (USSD), Short Message Services (SMS), robocalls, and feature phones. The system also provides a common platform for sharing FMD outbreaks data and events to other stakeholders based on the system's privileges. In this study, a closed-ended interview using a questionnaire was used for data collection. The PHP hypertext processor, jQuery, HTML, JSON, JavaScript, Apache web server, and MySQL database were used for developing the system.
\end{abstract}

\section{Introduction}

Foot-and-Mouth Disease (FMD) is a transboundary disease caused by the virus from the Picornaviridae family. The disease affects domestic and wild cloven-hooved animals such as sheep, goats, pigs, and buffaloes [1]. Adult animals can survive an FMD attack; however, FMD impacts their milk production and growth. Also, the presence of FMD in livestock hinders international trade. Young animals sometimes die from FMD [2]. There are currently seven known serotypes of FMD virus (A, O, C, SAT1, SAT2, SAT3, and Asia1) and many more subtypes in the world. Type A, O, SAT1, SAT2, and SAT3 are present in Tanzania [2]. FMD is transmitted from one animal to another through the following mechanisms: direct contact or indirect contact, e.g., by contact with contaminated inanimate objects (often referred to as fomites). FMD is currently present in Asia and Africa and one country in South America. [3]. In Tanzania, Gairo is among the districts facing FMD challenges several times. Currently, the disease has no cure, and vaccination is the most important control measure for FMD. However, vaccines do not protect between serotypes, and sometimes protection within a serotype is limited. Therefore, the vaccines must match the virus strain circulating in livestock for effective prevention. FMD-free countries prohibit the importation of FMD-vaccinated animal products or only 
allowed it after additional risk-mitigating measures, which reduces the possibilities of international trade. Since FMD is a notifiable disease, immediate information sharing during the outbreaks is mandatory for mitigating the disease. The big challenge in Gairo district is a long chain when communicating FMD outbreaks among livestock stakeholders. Normally, the ward veterinarians receive FMD outbreaks from livestock keepers either by routine visits or by phone calls from immediate livestock keepers. Sometimes, veterinarians leave unreported cases due to unfriendly terrains that hinder access to remote livestock keeping communities, especially in rainy seasons. Once the veterinarians receive the information, report the incident to the district veterinary officer (DVO) either by calling or visiting the DVO office. The DVO forwards the information to the Directorate of Veterinary Service that has the mandate of uploading data to the global surveillance systems. Sometimes, communication breakdown may happen if somebody is irresponsible along the reporting chain. Similarly, whenever there is a threat of FMD, the veterinarians use to visit individual livestock keepers to alert them about the disease and precaution measures that could be taken efficiently using the information system. Sometimes, the current reporting mechanism causes delay and insufficient information for controlling FMD in Gairo district. Also, the process of visiting livestock keepers for collecting or giving information is costly and requires a greater number of veterinarians for it to be effective.

Some countries use surveillance systems for communicating animal disease outbreaks, including FMD, which replace the paper-based reporting mechanism. However, the systems depend on the input data from veterinarians, laboratories, and other healthcare providers that act as main sources of information [4]. The systems contradict other surveillance studies that emphasize the fact that livestock keepers should be the primary source of outbreak information to detect the disease early since the FMD has no cure [5]. Also, few surveillance systems enable livestock keepers to report disease outbreaks direct to the system. However, such systems failed to consider livestock keepers' demographic characteristics on their technology to access the surveillance systems. For example, such systems are web-based and emphasize on the use of smartphone for reporting disease outbreaks, while the majority of livestock keepers, especially in developing countries, own feature phones which cannot browse the Internet $[6,7]$.

Similarly, the system communicates the disease outbreaks and precaution measures through websites, while livestock keepers lack skills and devices for browsing the Internet $[8,9]$. Also, few systems are integrated with Short Message Service (SMS) only for alerting the disease outbreaks, while some of the livestock keepers, especially in developing countries, have no formal education and cannot read SMS [10]. The partial involvement of livestock keepers, who are significant stakeholders in animal diseases control, contributes to the factors affecting information flow to the existing surveillance systems. This study explores the challenges of communicating FMD events among livestock stakeholders in Gairo district and proposes an information system to solve that challenge. The system will enhance the early detection of FMD as livestock keepers will report the disease outbreaks directly to system [7]. It will improve FMD awareness by sharing FMD events such as outbreaks, clinical signs, and precaution measures direct to livestock keepers in real time. Not only that, but also the system will remove chain when reporting FMD outbreaks among livestock stakeholders in Gairo by proving a common platform for sharing FMD data. The robot calls (robocalls) and Unstructured Supplementary Service Data (USSD) parts of the proposed system will also enhance the existing surveillance systems' operations. The robocalls are automatic computer-generated mobile calls from a computer program that can dial many phone numbers at once and play a prerecorded or computer-generated voice message to anyone who answers the voice call [11].

\section{Methodology}

2.1. Description of the Study Area. There are many districts in Tanzania with a larger number of cattle compared to Gairo. However, Gairo was selected as a study area because of the easy availability of three livestock farming systems named zero-grazing, agropastoralism, and pastoralism in contrast to other districts whereby one farming system may dominate. Therefore, the researcher was convinced that Gairo district would provide sufficient information/data for the study. Usually, zero-grazing is available in urban areas, agropastoralism is practiced in semiurban areas, while pastoralism is available in rural areas long-distanced from urban centres. Gairo district is in the Morogoro region and located between the latitude $36^{\prime} 500 \mathrm{E}-37^{\prime} 200 \mathrm{E}$ and longitude $6^{\prime} 400$ S-5'500S along the Morogoro-Dodoma region road (Figure 1).

2.2. Sample Size Determination for Respondents. The closedended interview using questionnaires was conducted involving 180 livestock keeping households from 6 villages of Gairo district named Kilama, Chogoali, Chakwale, Kilimani, Gairo town, and Ibuti. The interviewees were the heads of the families, regardless of their gender. The number of households to be interviewed was selected by using the rule of thumb to determine the sample size of households which states that a minimum sample size of 25-30 households is appropriate for a village that ranges in size from 100 to 500 families [12]. As a result, 30 households from each village were interviewed. To obtain the number of villages to be interviewed, the researchers used a stratified sampling technique to group 54 Gairo district villages into 3 groups based on livestock farming systems [13]. Hence, the 54 villages were divided into the zero-grazing group, agropastoralism group, and pastoralism group of villages [13]. Thereafter, the 3 groups were listed in the Excel sheet, and 2 villages were randomly selected from each group for data collection. During the interview, the households were randomly chosen to avoid biases. 

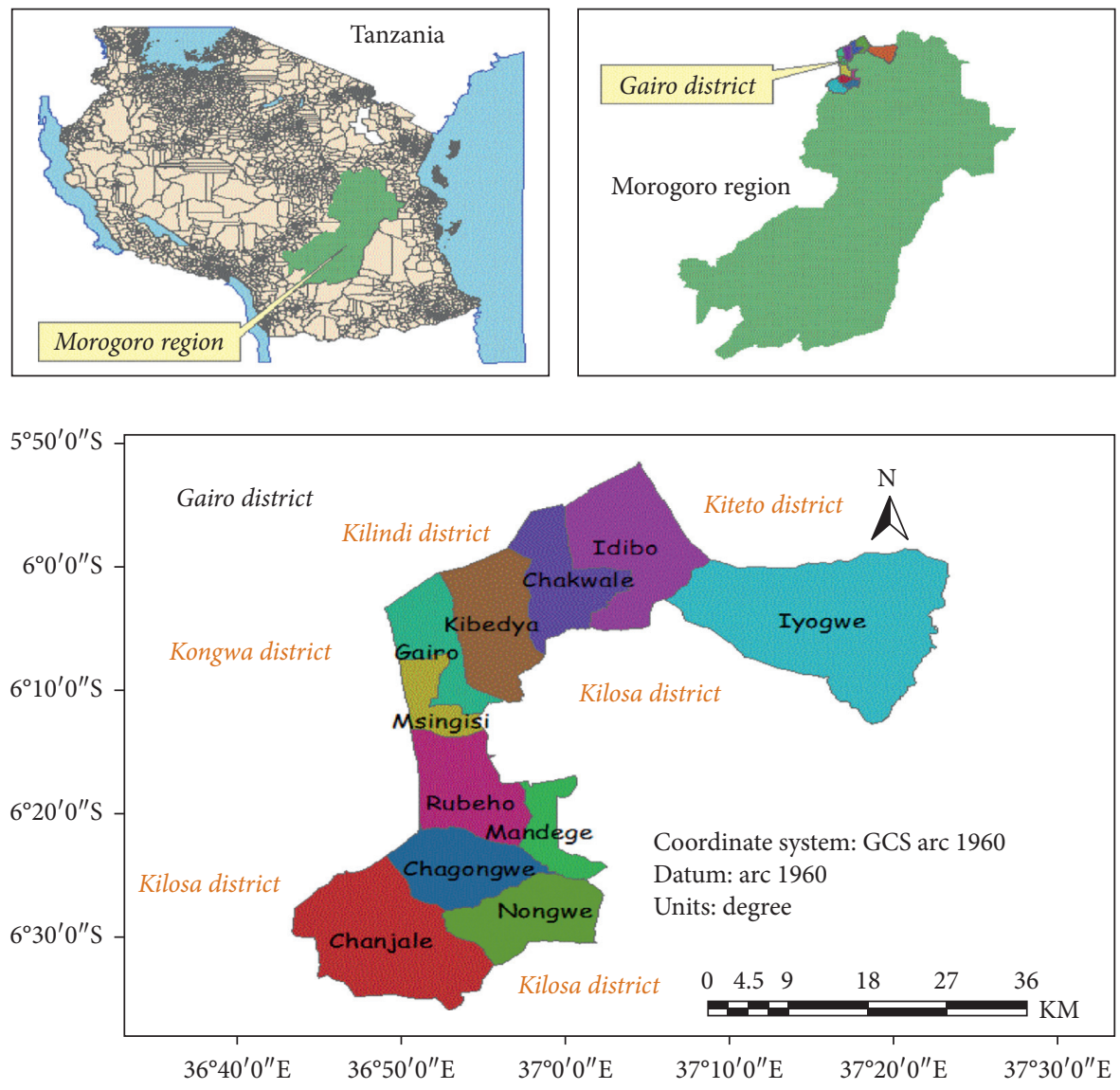

FIgURE 1: A map of Gairo district.

2.3. Data Collection and Analysis. Both multiple-response and single-response questions were used during data collection. The questions were formulated to gather the following information: (1) FMD status in Gairo district, (2) the livestock keepers demographic characteristics, (3) the time taken to receive information during FMD outbreaks in livestock keeping communities, and (4) sources of FMD outbreaks information. Also, the location in terms of latitude and longitude of each household was noted after the interview for generating spatial distribution maps (Figure 2). Furthermore, five-year (2015-2019) FMD outbreaks secondary data for all 54 villages in the study area were collected from VET offices headquarter to determine FMD trend (Figure 3 ). The livestock keepers' demographic characteristics data were purposely collected to determine the appropriate technologies that could be used for communicating FMD events in Gairo district. The Statistical Package for the Social Sciences (SPSS) was used for generating frequency distributions table for the data. Similarly, Aeronautical Reconnaissance Coverage Geographic Information System (ArcGIS) was used for rendering maps in this study (Figures 1 and 2).

2.4. System Design and Implementation. The PHP hypertext processor, JQuery, HTML, JSON, and JavaScript were used as the programming language during system implementation. The MySQL database was also used for storing data and feature phones and computers for testing and hosting the system. Not only that, but also USSD and robocalls were used for reporting and alerting FMD outbreaks. Lastly, Microsoft Visio software was used for drawing the system architecture diagram (Figure 4).

\section{Results}

3.1. FMD Status in Gairo District. During determining the FMD status, 170 livestock keepers out of 180 responded to the question that either they had already observed FMD infection in their cattle or not. The question was a single-response question. The livestock keepers responded "yes" to the question, asking to mention at least three FMD clinical signs to validate their answers. The data found that 133 (78\%) of the interviewed livestock keepers had already observed FMD infection in their cattle (Table 1). The larger number was experienced in pastoralist community that $97 \%$ of them had already observed FMD infection in their cattle, followed by agropastoral community, 93\% (Table 1). In contrast, only $44 \%$ was observed in the zero-grazing community.

3.2. Livestock Keepers' Demographic Characteristics. One hundred eighty (180) livestock keepers were interviewed to identify the categories of mobile phones they own and usage and their education level. The researcher used multiple- and single-response questions, and the number of responses varies according to the question. The data found that $91 \%$ of 


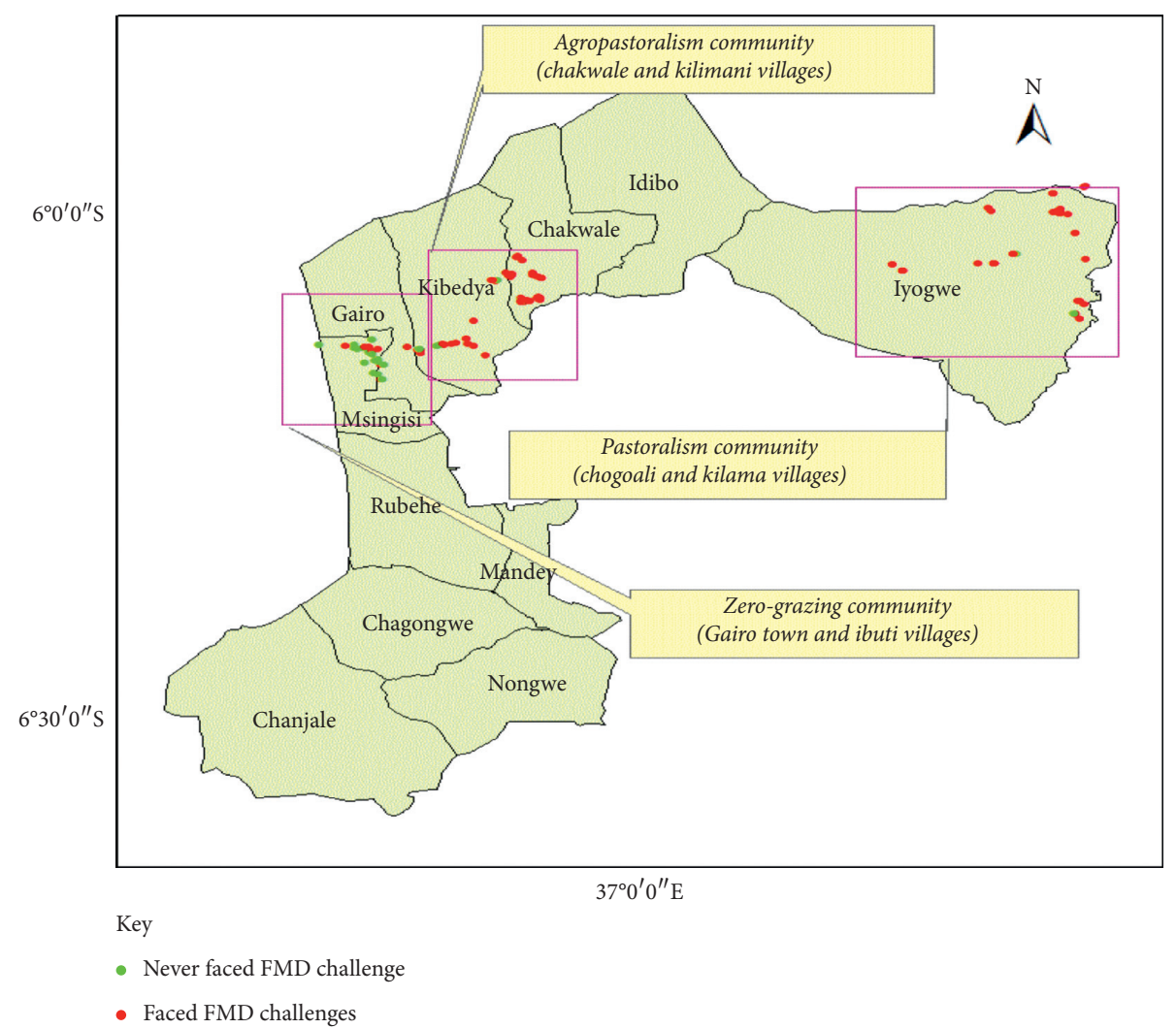

FIGURE 2: Spatial distribution of FMD surveyed households in the Gairo district.

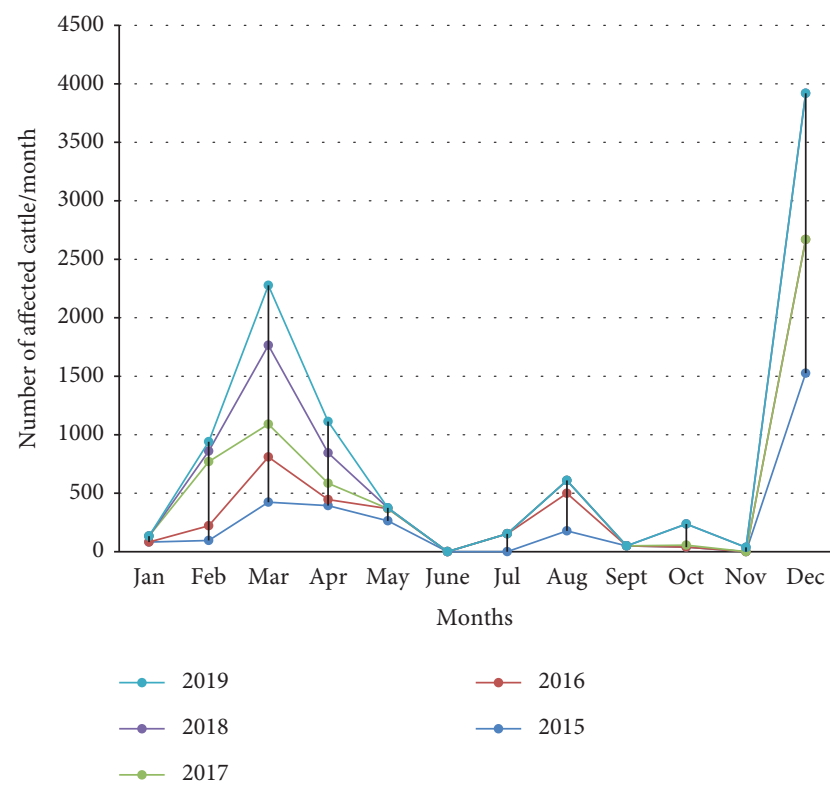

FIGURE 3: FMD-affected cattle in the Gairo district by the year (2015-2019).

livestock keepers own feature phones and 9\% own smartphones (Table 2). Most livestock keepers used mobile phones to make and receive voice calls and send and receive Short Message Services (SMS) (Table 2). Not only that, but also $60 \%$ of livestock keepers had primary school education, and $33 \%$ had no formal education at all (Table 2).
TABLE 1: Frequencies of livestock keepers who have already faced FMD challenges.

\begin{tabular}{lccc}
\hline Livestock farming system & Responses & Frequency & Percent \\
\hline \multirow{3}{*}{ Zero-grazing $(N=55)$} & No & 31 & 56 \\
& Yes & 24 & 44 \\
& Total & 55 & 100 \\
Agropastoral $(N=57)$ & No & 4 & 7 \\
& Yes & 53 & 93 \\
& Total & 57 & 100 \\
Pastoral $(N=58)$ & No & 2 & 3 \\
& Yes & 56 & 97 \\
& Total & 58 & 100 \\
\hline
\end{tabular}

3.3. The Observed Relationship between the FMD Outbreaks and Seasons of the Year in Gairo District. Figure 3 indicates the number of affected cattle per month for five years (Jan 2015 to May 2019). It seems that most FMD outbreaks had been reported in January-May, August, October, and December. However, there are very few cases in July, September, and November, and no cases were reported in June for the past five years consecutively. The reason for this variation was not identified in this study.

3.4. The Time Taken to Receive Information about FMD Outbreaks and Sources of FMD Outbreaks Information in Livestock-Keeping Communities. The study revealed a delay in information flow in livestock-Keeping Communities during the FMD outbreak. The data indicated that most 
TABLe 2: Frequencies of livestock keepers' demographic characteristics.

\begin{tabular}{|c|c|c|}
\hline Variables & Frequencies & Percent (\%) \\
\hline \multicolumn{3}{|l|}{ Livestock keepers owning mobile phones $(N=170)$} \\
\hline No & 27 & 16 \\
\hline Yes & 143 & 84 \\
\hline Total & 170 & 100 \\
\hline \multicolumn{3}{|l|}{ Mobile phone usage $(N=143)$} \\
\hline Smartphone & 13 & 9 \\
\hline Feature phone & 139 & 91 \\
\hline Total & 152 & 100 \\
\hline \multicolumn{3}{|l|}{ Level of education $(N=171)$} \\
\hline Primary school & 103 & 60 \\
\hline Secondary school & 10 & 6 \\
\hline University & 1 & 1 \\
\hline No formal education & 57 & 33 \\
\hline Total & 171 & 100 \\
\hline \multicolumn{3}{|l|}{ Mobile phone usage $(N=144)$} \\
\hline Sending and receiving SMS & 114 & 39 \\
\hline Making and receiving calls (including robocalls) & 141 & 48 \\
\hline Surfing the Internet & 10 & 3 \\
\hline Social network & 11 & 4 \\
\hline Other uses & 19 & 6 \\
\hline Total & 295 & 100 \\
\hline
\end{tabular}

livestock keepers got information one day after the disease outbreaks (Table 3). Thus, 79\% of pastoralism, $74 \%$ of agropastoralism, and $67 \%$ of zero-grazing got information more than one day after the FMD outbreaks (Table 3). Also, livestock keepers mostly communicate FMD incidents/outbreaks and control measures among themselves rather than getting official information from liable sources such as local and regional VET offices or veterinarians (Table 3). Since most livestock got FMD outbreaks information more than one day after the outbreaks and disease signs can appear in animals within 2 to 14 days after exposure [14], that means the probability of getting information while animals have already been affected is higher. Not only that, but also the majority of livestock keepers receive FMD outbreaks information from other livestock keepers and just hear rumours from their nearby villages. However, very few receive information from veterinarians. Generally, there are no official ways of communicating FMD events among livestock stockholders in the district.

\section{Discussion}

Due to the lack of official ways of communicating FMD outbreaks in the Gairo district, which causes delay and insufficient information for controlling FMD (Table 3), the researcher is in the opinion that if a suitable communication mechanism is established between livestock keepers and other stakeholders may reduce the impact of the FMD in the district. Information systems play a significant role in developing different practical approaches to prevent, detect, respond to, and manage infectious disease outbreaks on plants, animals, and humans $[6,8,9,15]$. Similarly, by considering livestock keepers' demographic characteristics, one may use information technology for communicating FMD among livestock stakeholders through a software system that is specifically developed for monitoring FMD (Table 3). The data showed that Gairo district has a reasonable number of livestock keepers owning feature phones and mostly used them for SMS and voice calls (Table 2). Therefore, the study suggests that SMS, USSD code, and automatic broadcasting calls (robocalls) may be the best means of communicating FMD incidents/outbreaks among livestock farmers and other livestock stakeholders in Gairo district. Technically, SMS, USSD, and robocalls will satisfy those who have a primary school level and above who can read and write SMS.

In contrast, robocalls alone will benefit those who have no former knowledge, and it is believed that most cannot read and write SMS. However, all the mentioned technologies will satisfy most livestock keepers because the majority own feature mobile phones. Thus, the study suggests the information system named "The Monitoring System for Transboundary FMD" embedded with the mentioned technologies for broadcasting FMD awareness and real-time outbreaks to livestock keepers, enabling early reporting and detection of FMD outbreaks. The information system may help maintain FMD awareness of livestock keepers by sending regular announcements in SMS and robocalls reminding them about the precaution measures, negative impacts, clinical signs, and mode of disease transmission. Similarly, the system enables early detection of FMD by allowing livestock keepers to report the disease outbreaks as soon as possible using USSD code or SMS with their feature phone. Finally, the system will provide FMD outbreaks secondary and current data for decision making by policymakers. Also, veterinarians and researchers may use data for research purpose. 
TABLE 3: Time taken by livestock keepers to receive FMD outbreaks information from different sources and sources of FMD information.

\begin{tabular}{|c|c|c|c|}
\hline Livestock farming system & Variables & Frequencies & Percent (\%) \\
\hline \multicolumn{4}{|c|}{ Time taken by livestock keepers' communities to receive information during FMD outbreaks } \\
\hline \multirow{6}{*}{ Zero-grazing $(N=39)$} & Within 1 hour & 2 & 5 \\
\hline & Within 6 hours & 1 & 3 \\
\hline & Within 12 hours & 3 & 8 \\
\hline & Within 1 day & 4 & 10 \\
\hline & More than 1 day & 26 & 67 \\
\hline & No information at all & 3 & 8 \\
\hline \multirow{11}{*}{ Agropastoralism $(N=39)$} & Total & 39 & 100 \\
\hline & Within 1 day & 6 & 15 \\
\hline & Within 6 hours & 0 & 0 \\
\hline & Within 12 hours & 0 & 0 \\
\hline & Within 1 day & 0 & 0 \\
\hline & More than 1 day & 29 & 74 \\
\hline & No information at all & 4 & 10 \\
\hline & Total & 39 & 100 \\
\hline & Within 1 hour & 1 & 2 \\
\hline & Within 6 hours & 3 & 6 \\
\hline & Within 12 hours & 0 & 0 \\
\hline \multirow[t]{4}{*}{ Pastoralism $(N=52)$} & Within 1 day & 6 & 12 \\
\hline & More than 1 day & 41 & 79 \\
\hline & No information at all & 1 & 2 \\
\hline & Total & 52 & 100 \\
\hline \multicolumn{4}{|c|}{ Sources of FMD information in livestock keepers communities } \\
\hline \multirow{6}{*}{ Zero-grazing $(N=43)$} & VET professional & 11 & 19 \\
\hline & Other livestock keepers & 39 & 67 \\
\hline & Special meetings & 1 & 2 \\
\hline & Just hearing rumours & 7 & 12 \\
\hline & Others & 0 & 0 \\
\hline & Total & 58 & 100 \\
\hline \multirow{6}{*}{ Agropastoralism $(N=49)$} & VET professional & 5 & 8 \\
\hline & Other livestock keepers & 44 & 75 \\
\hline & Special meetings & 0 & 0 \\
\hline & Just hearing rumours & 4 & 7 \\
\hline & Others & 6 & 10 \\
\hline & Total & 59 & 100 \\
\hline \multirow{6}{*}{ Pastoralism $(N=55)$} & VET professional & 0 & 0 \\
\hline & Other livestock keepers & 54 & 91 \\
\hline & Special meetings & 1 & 2 \\
\hline & Just hearing rumours & 0 & 0 \\
\hline & Others & 4 & 7 \\
\hline & Total & 59 & 100 \\
\hline
\end{tabular}

\section{Recommended Information System}

The Monitoring System for Transboundary FMD is a web-based system like other famous animal disease surveillance systems, but with extra functionality such as SMS, USSD code services, and automatic voice calls (robocalls).

5.1. System Architecture. The system developed using PHP hypertext processor, JQuery, HTML, MySQL database, Apache web server, JSON, and JavaScript. The MySQL database and Apache web server are available by installing the XAMPP software package. The SMS gateway and voice gateway are installed in the system for providing voice and SMS broadcast services. The SMS modem and voice modem are attached to the server hardware via USB ports (Figure 4). The modems are connected to the SMS and a voice gateway through the software's setting menu. The monitoring system for transboundary Foot-and-Mouth Disease comprises two modules: (a) FMD awareness maintenance module and (b) FMD incidents/outbreaks reporting module. The modules developed as a looping PHP script that automatically executes every $30 \mathrm{sec}-$ onds. The Script simultaneously checks the recent verified, reported FMD incident/outbreak in permanent database 2 (PDB2) and the broadcast time interval allocated to the FMD outbreaks, precaution measures, clinical signs, and negative impacts of FMD in permanent database 1 (PDB1) (Figure 4).

\subsection{Descriptions for System Components}

5.2.1. FMD Awareness Maintenance Module. This module regularly broadcasts FMD precaution measures, clinical signs, and negative impacts in the form of SMS and voice to livestock keepers. The researchers, laboratories, and regional and 


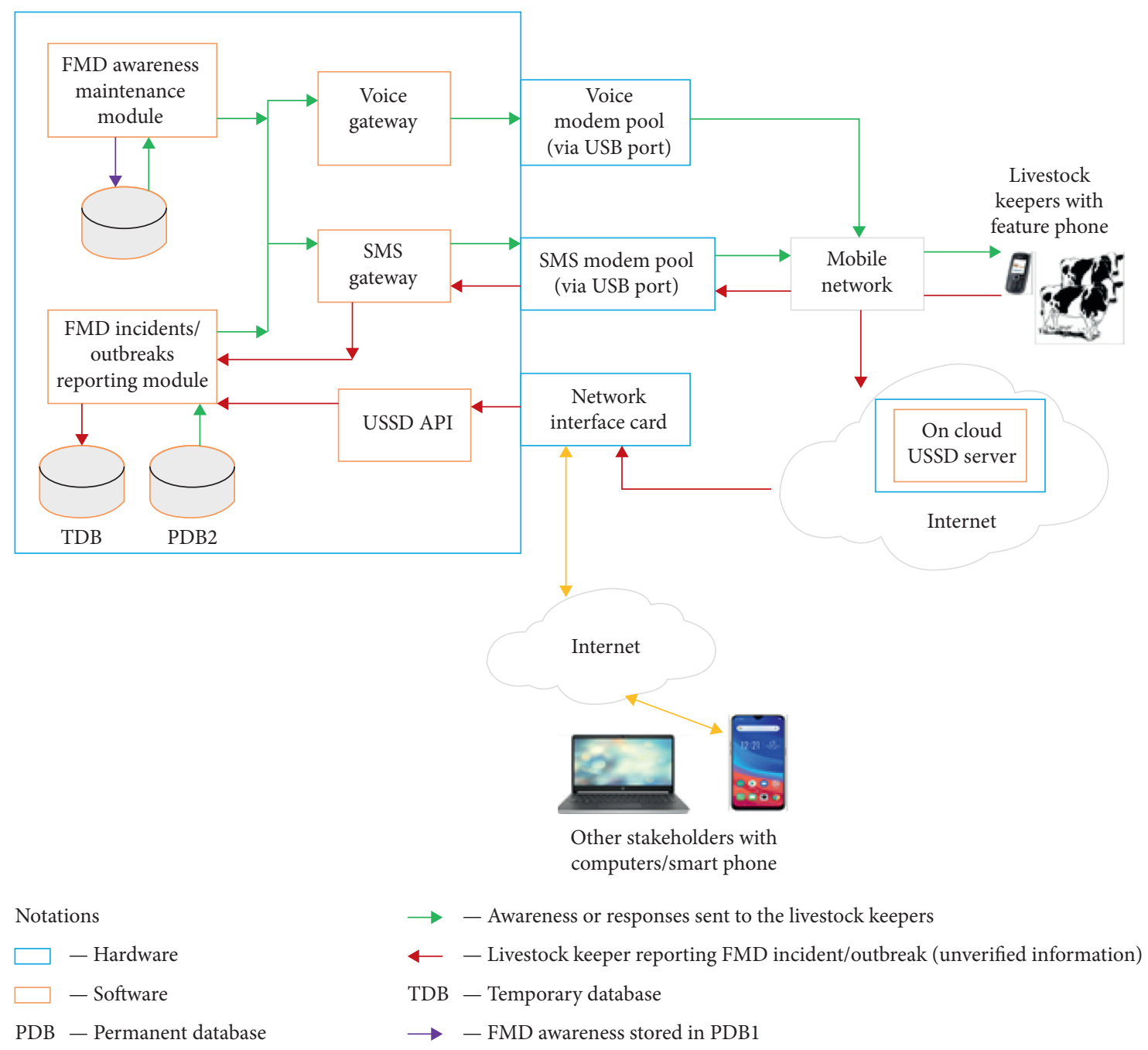

Figure 4: Block diagram of system architecture.

local VET officers store this information in permanent database 1 together with their broadcasting time interval. The data uploaded to the system (PDB1) is either the name of a prerecorded audio file (.wav) or the text descriptions of the FMD awareness. However, the actual prerecorded audio file (.wav) is uploaded to the voice modem using the voice gateway software [16]. The module compares the last broadcast time of each stored FMD awareness with the operating system time. If the difference between them is greater than the assigned FMD awareness broadcast time interval, the system broadcasts that particular FMD awareness to livestock keepers. The process repeats every 30 seconds. The text descriptions were broadcasted to all livestock keepers in the form of SMS using SMS gateway through SMS modem. Similarly, the voice file is sent as an automatic voice call (robocalls) using a voice gateway through the voice modem. The robocalls are automatic computer-generated mobile calls from a computer program that can dial many phone numbers at once and play a prerecorded or computer-generated voice message to anyone who answers the voice call [11]. In this case, the prerecorded message is our FMD awareness (.wav) files.

5.2.2. FMD Incidents/Outbreaks Reporting Module. The livestock keepers may report the FMD outbreaks using USSD by dialing a specific USSD code. When the request is initialized, a USSD menu will pop up with a list of village numbers and names (e.g., 1-Kilama village and 2-Chogoali village) that allow the livestock keeper to send a specific village number to the system. The alternative way is to send the village number to the system using SMS. Once the information received is by the system, it is tagged as unverified and stored in the temporary database. The system captures mobile phone numbers of the livestock keepers whenever they report FMD incidents/outbreaks via USSD code or SMS. The veterinarians use the stored mobile phone numbers for tracing up the validity of the information immediately. If the temporary information is valid, the system transfers it to the permanent database 2 (PDB2) after 
the veterinarian clicks the confirmation button on the web page based on his privilege.

Consequently, the audio message and SMS are sent to all livestock keepers, informing them about the outbreak and immediate precaution measures. Otherwise, the system deletes the unverified information from a temporary database after the veterinarians click the discard button, and feedback is sent to only the one who reported the incident, informing him that the information was invalid. Anybody can view the number of unverified and valid incidents on the home page of the system.

5.3. Voice Gateway. SMSDeliverer was used as a voice gateway for broadcasting voice [16]. Voice gateway provides automatic voice call services by broadcasting FMD awareness, FMD incident, or outbreak prerecorded audio files to livestock keepers through the voice modem pool attached to the server via USB port. The voice gateway acts as a communication interface between the FMD monitoring system and the voice modem pool. The actual prerecorded audio files are stored in the modem using the voice setting panel of voice gateway software. The information system may broadcast a specific audio file by referring to its file name in permanent database 1 (PDB1) and database 2 (PDB2). The modules use HTTP GET request to broadcast the prerecorded audio file by specifying the audio file name with the request. Therefore, the HTTP GET request acts like a simple API that connects the FMD monitoring system and voice gateway.

5.4. SMS Gateway. Diafaan SMS Server was used as an SMS gateway. SMS gateway provides SMS services by broadcasting FMD awareness, FMD incident, or outbreak descriptions to livestock keepers via SMS modem pool connected to the server. The SMS modem pool is connected to the server via a USB port. The SMS gateway act as a communication interface between the FMD monitoring system and the SMS modem pool.

5.4.1. Voice Modem Pool. 3G SIMCOM modem pool with 4 ports was used for voice broadcasting [17]. Any modem pool with the capability of SIMCOM modems can be used. Each modem contains a SIM card for accessing the mobile network. The SIMCOM are modems with the ability to execute "AT" commands and storing audio files in (.wav) format. The prerecorded audio files were inserted into the modem using the voice gateway software [16]. The monitoring system plays the audio files by referring to their names in permanent PDB1 and PDB2 (Figure 4).

5.4.2. SMS Modem Pool. Huawei modem E220 was used for routing SMS. The four Huawei E220 modems connected using a USB hub to form a modem pool. The modem pool connects to the computer USB port through the USB hub. Each modem contains a SIM card for accessing the mobile network.
5.5. Feature Phones. Feature phones enable communication between livestock keepers and the Monitoring System for Transboundary FMD.

5.6. USSD Application Program Interface (API). The USSD Application Program Interface is a part of the FMD incident/ outbreaks reporting module. The API enables communication between the cloud USSD server and system. The API periodically queries the newly reported outbreak information (village number and reporter mobile phone number) from the USSD server and stores it to the temporary database. This information was reported using feature phones.

5.7. Smartphones and Computers. Smartphones and computers enable veterinarians to verify the reported outbreak information. Also, other stakeholders may use smartphones and computers to access the system because it is web based.

\section{Conclusion}

Many private and government institutions in the world performed several types of research and introduced several ways of combating FMD. Furthermore, the research findings published in various places, including but not limited to research journals, magazines and surveillance systems. This study found that some livestock keepers in Gairo district still lack knowledge of FMD control regardless of the literature's existence. The reason is the lack of knowledge and devices for accessing the materials. For this reason, researchers are in the position to advise nonFMD-free declared countries to analyze their livestock-keeping communities to find various alternatives for sharing materials and animal disease information with livestock-keeping communities through their resources. For example, this study used feature phones to share FMD events in Gairo district after analyzing livestock keepers' demographic characteristics. Finally, this study suggests further research in the Gairo district on why more FMD cases are observed in January-May, August, October, and December.

\section{Data Availability}

The data that support the findings of this study are openly available at https://drive.google.com/file/d/ 16qmp7ijz2JY_fuihovZRMXnJ1amIVqOw/view? usp=sharing in Excel sheet file format.

\section{Conflicts of Interest}

The authors declare that they have no conflicts of interest regarding the publication of this paper.

\section{Acknowledgments}

Towards this research's success, the authors appreciate the contribution of the following: firstly, the African Development Bank for providing funding; secondly, the management of Gairo district for accepting Gairo district to be the study area; and lastly, veterinarians Mr. Godbless Emanuel and Mr. Emanuel Kasanga for the assisting research team 
during data collection. This research was funded by the African Development Bank (AFDB) through the Ph.D. Scholarship at the Nelson Mandela African Institution of Science and Technology, Arusha, Tanzania. The Bank sponsored the Ph.D. student as well as provided remuneration to the supervisors of the student. Both a student and supervisors are the authors of this paper.

\section{References}

[1] C. J. Kasanga, W. Yamazaki, V. Mioulet et al., "Rapid, sensitive and effective diagnostic tools for foot-and-mouth disease virus in Africa," Onderstepoort Journal of Veterinary Research, vol. 81, no. 2, pp. 1-5, 2014.

[2] Ministry of Livestock and Fisheries-Uganda: Current Status of Foot and Mouth Disease in Tanzania [White Paper], 2019, https://rr-africa.oie.int/wp-content/uploads/2018/ 07/19-michael-j-madege-tanzania-country-presentationfmd-roadmap.pdf.

[3] Food and Agriculture Organization (FAO) of the United Nations, Foot-and-Mouth Disease Situation, Food and Agriculture Organization, Quebec, CA, USA, 2019, http://www. fao.org/3/ca6346en/ca6346en.pdf.

[4] G. J. Milinovich, G. M. Williams, A. C. A. Clements, and W. Hu, "Internet-based surveillance systems for monitoring emerging infectious diseases," The Lancet Infectious Diseases, vol. 14, no. 2, pp. 160-168, 2014.

[5] M. McLaws, C. Ribble, W. Martin, and J. Wilesmith, "Factors associated with the early detection of foot-and-mouth disease during the 2001 epidemic in the United Kingdom," The Canadian Veterinary Journal La Revue Veterinaire Canadienne, vol. 50, no. 1, pp. 53-60, 2009.

[6] ProMED-mail, Map of the Latest Alerts on Infectious Disease Around the World, ProMED-mail, Boston, MA, USA, 2018, https://www.promedmail.org/.

[7] S. M. Thumbi, M. K. Njenga, E. Otiang et al., "Mobile phonebased surveillance for animal disease in rural communities: implications for detection of zoonoses spillover," Philosophical Transactions of the Royal Society B: Biological Sciences, vol. 374, no. 1782, p. 20190020, 2019.

[8] Health Map, Map of the Latest Alerts on Infectious Disease Around the World, University of Washington, Washington, DC, USA, 2018, https://www.healthmap.org/en/.

[9] M. Mwabukusi, E. D. Karimuribo, M. M. Rweyemamu, and E. Beda, "Mobile technologies for disease surveillance in humans and animals," Onderstepoort Journal of Veterinary Research, vol. 81, no. 2, pp. 1-5, 2014.

[10] M. R. Hassan, Assessment of Efficiency in Livestock Markets in Tanzania: The Case of Primary Livestock Markets in Morogoro Region, University of agriculture, Morogoro, Tanzania, 2009, http://www.suaire.suanet.ac.tz:8080/xmlui/bitstream/handle/ 123456789/688/HASSAN MGANI RUPINDO 2009.pdf.

[11] The Conversation, Rob calls are unstoppable-3 questions answered about why your phone won't quit ringing, 2019, https://theconversation.com/robocalls-are-unstoppable-3questions-answered-about-why-your-phone-wont-quit-ri nging-108554.

[12] A. Angelsen, H. Larsen, J. Lund, C. Smith, and S. Wunder, Measuring of Livelihood and Environmental Dependences, Earthscan publishing for a sustainable future, Washington, DC, USA, 2011.

[13] C. R. Kothari, "Research methodology, methods and techniques," Edited by A. Road and Daryaganj, Eds., p. 62, New
Age International (P) Limited, Publishers, New Delhi, India, 2008.

[14] M. J. Grubman and B. Baxt, "Foot-and-Mouth disease," Clinical Microbiology Reviews, vol. 17, no. 2, pp. 465-493, 2004.

[15] D. Aswini, S. Santhya, T. S. Nandheni, and N. \&Sukirthini, "Cattle health and environment monitoring system," International Research Journal of Engineering and Technology (IRJET), vol. 4, no. 3, pp. 1899-1903, 2017.

[16] SMSDeliverer, MMS \& SMS Software, SMSDeliverer, Chennai, India, 2020, https://www.smsdeliverer.com/onlinehelp/ index.htm?page=Send_SMS_by_HTTP_API.htm.

[17] 2020 https://atcb2b.en.china.cn/851114-3g-modem China.cn. "Shenzhen Antecheng Technology Co., Ltd - 4/8/16/32/64 ports modem pool.

[18] Food and Agriculture Organization (FAO) of the United Nation, Tanzania at a Glance, Food and Agriculture Organization, Quebec, CA, USA, 2020, http://www.fao.org/ tanzania/fao-in-tanzania/tanzania-at-a-glance/en/. 